\title{
ENTRE A SEDE E O LUCRO: UM POSSÍVEL CASO DE VIOLAÇÃO DOS DIREITOS HUMANOS PELA PRIVATIZAÇÃO DA ÁGUA NO BAIRRO DA TAQUARA EM DUQUE DE CAXIAS - RJ
}

\author{
BETWEEN THIRST AND PROFIT: A POSSIBLE CASE OF HUMAN RIGHTS \\ VIOLATION BY THE PRIVATIZATION OF WATER IN THE TAQUARA DISTRICT OF \\ DUQUE DE CAXIAS - RJ
}

\author{
André Luiz Barreto Mello ${ }^{(1)}$ \\ Mestrando em Planejamento Urbano e Regional (IPPUR/UFRJ). Bacharel em Ciência Ambiental (UFF). \\ Maria Clara Gonçalves Arouca ${ }^{(2)}$ \\ Mestranda em População, Território e Estatísticas Públicas (ENCE/IBGE). Bacharela em Ciência Ambiental (UFF). \\ E-mail ${ }^{(1)}$ : andre_mello@id.uff.br
}

\section{RESUMO}

A cidade de Duque de Caxias apresenta índices insuficientes de abastecimento de água e esgotamento sanitário, quadro este que é ainda mais dramático no bairro da Taquara e adjacências. O presente artigo objetiva trazer insumos para complementar a discussão sobre a questão hídrica da região a partir da chegada de um empreendimento da Coca-Cola Andina - em área adjacente ao Parque Natural Municipal da Taquara -, refletindo sobre como a privatização da água acentua as desigualdades sociais e inviabiliza a efetivação dos direitos humanos à água e ao esgotamento sanitário. Por intermédio de relatos de pesquisadores da região e análise documental, observou-se que, com a chegada da fábrica na região, diversos conflitos eclodiram, desde desmatamento indevido até denúncias de moradores sobre o rebaixamento do lençol freático acentuado pelo uso da água pela corporação, o que agrava ainda mais a já calamitosa insegurança hídrica.

\begin{abstract}
The city of Duque de Caxias has insufficient levels of water supply and sanitation, that is even more dramatic in the neighborhood of Taquara and surrounding areas. This article aims to bring inputs to complement the discussion about the water issue in the region after the arrival of a Coca-Cola Andina enterprise - in an area adjacent to the Taquara Municipal Natural Park -, reflecting on how the privatization of water accentuates social inequalities and makes the realization of human rights to water and sanitation unfeasible. Through reports from local researchers and document analysis, it was observed that, with the arrival of the factory in the region, several conflicts have erupted, from improper deforestation to complaints from residents about the lowering of the water table accentuated by the corporation's use of water, which further aggravates the already calamitous water insecurity.
\end{abstract}

Palavras-chave: DHAES. Água. Duque de Caxias. Conflito. Coca-Cola Andina.

Keywords: Human rights to water and sanitation. Water. Duque de Caxias. Conflict. Coca-Cola Andina.

\section{INTRODUÇÃO}

A Resolução nº 64/292, de 2010, da Assembleia Geral da Organização das Nações Unidas (ONU), foi um importante marco para o saneamento, reconhecendo os direitos à água potável e ao esgotamento sanitário (DHAES) como um direito humano essencial para o pleno gozo da vida e de todos os direitos humanos. Ribeiro (2015) analisa que esse direito não é reconhecido como direito fundamental pela Constituição brasileira, mas ela o prevê em alguns dispositivos, como a Lei Federal 11.445/2007 que estabelece as diretrizes nacionais sobre o saneamento básico.

Ressalta-se que o saneamento une questões sociais referentes à dignidade humana e reprodução da 
vida com a temática ambiental, visto que as necessidades de abastecimento de água e saneamento basilares para a realização de outros direitos ${ }^{1}$ - estão intimamente ligadas à preservação dos recursos hídricos. Essa interação sugere que a natureza necessita de proteção jurídica e moral para assegurar os direitos humanos. Gudynas (2019) argumenta que a vinculação dos direitos humanos com a conservação ambiental foi fundamental para a formulação de políticas públicas que assegurassem a democracia e a dignidade humana. Um exemplo é a criação do SNUC, de modo que a moralidade imposta em proteger o meio ambiente se respalda na proteção e efetivação dos direitos humanos.

Em Duque de Caxias, o Parque Natural Municipal da Taquara (PNMT) é uma dessas unidades de conservação com relevante importância para a proteção dos mananciais hídricos - o rio Taquara contribui para assegurar a realização progressiva dos DHAES na região. Contudo, a Coca-Cola Andina instalou-se em área contígua ao PNMT, gerando conflito de interesses entre iniciativa privada e saúde coletiva, tensionando a efetivação desses direitos por parte do poder público.

Os municípios da Região Metropolitana do Rio de Janeiro (RMRJ), principalmente da Baixada Fluminense, são marcados por desigualdades referentes ao saneamento - consequência da sistemática desatenção em relação ao centro - devido à ineficácia e à descontinuidade de programas e projetos (BRITTO; QUINTSLR, 2020). Os dados do Sistema Nacional de Informações sobre Saneamento (SNIS) de 2019, apontam que o município de Duque de Caxias apresenta índice de atendimento urbano de esgoto de apenas $23,55 \%$ e índice de atendimento urbano de água de $81,7 \%$ (SNIS, 2020).

Desse modo, explicita-se a dificuldade do Estado em conciliar os imperativos pelo desenvolvimento econômico e a questão da preservação ambiental atrelada aos DHAES. Essa contradição torna-se perceptível no momento em que o Estado autoriza uma corporação altamente predadora de recursos hídricos se instale próxima a uma unidade de conservação que justamente tem como uma de suas finalidades a conservação dos recursos naturais.

Essa oposição de interesses é um traço marcante do processo de mercantilização da vida que, paulatinamente, pretende transferir o controle comunal de praticamente todo bem público para a iniciativa privada, com a justificativa de que o controle privado do uso e acesso aos bens naturais resultaria em melhor gestão, preservando-os e promovendo sua manutenção, ao passo que se estimula o culto irrestrito ao individualismo e à individualidade em detrimento das relações sociais outras, pautadas no comum, inviabilizando assim outras lógicas de reprodução e apropriação do espaço. (DARDOT; LAVAL, 2017; BORDALO, 2008).

A partir do exposto, considerando que a população de Duque de Caxias convive com ineficiência no acesso ao abastecimento de água e esgotamento sanitário, o presente estudo buscará trazer insumos para complementar a discussão sobre a questão hídrica da região a partir da chegada da Coca-Cola Andina no bairro da Taquara - em área adjacente ao PNMT -, refletindo sobre como a privatização da água acentua as desigualdades sociais e inviabiliza a efetivação dos DHAES.

$\mathrm{O}$ artigo estrutura-se em quatro seções. A primeira, já exposta, consiste na introdução e contextualização da temática. A segunda seção expõe a metodologia utilizada; a terceira aborda a relação entre o caso da Coca-Cola no bairro da Taquara e os DHAES; por fim, as considerações finais.

\section{METODOLOGIA}

A metodologia empregada consiste em revisão da literatura, buscando entender como os DHAES se relacionam com questões emergentes da contemporaneidade, como a chantagem locacional empregada pelas grandes corporações e sua consequente desmobilização social, a partir da criação de

\footnotetext{
${ }^{1}$ Os DHAES estão vinculados, dentre outros, ao direito à educação, ao passo que as escolas não funcionam sem água; à alimentação, visto que a água é o alimento mais básico, além de ser a fonte primária de energia para a agricultura; à moradia adequada vinculada à segurança e privacidade, principalmente se tratando da integridade física e moral das mulheres (ALBUQUERQUE, 2014).
} 
consensos que obstaculizam o comum pela comoditização da água.

Somado a isso, realizou-se entrevista aberta com a pesquisadora e moradora de Duque de Caxias, Marlúcia Santos de Souza, com o intuito de apreender a complexidade do caso a partir de sua leitura histórica e territorializada. Por fim, realizou-se levantamento de informações para a investigação das questões pertinentes ao estudo, em que foram consultados documentos oficiais e reportagens que versam sobre o caso.

\section{RESULTADOS E DISCUSSÃO}

A presente seção se orienta na mostra da área de estudo, onde se abordam dados sobre abastecimento de água e esgotamento sanitário, além de demonstrar alguns componentes para elucidação da complexidade do território, como o histórico que remonta às origens de empreendimentos de grande porte no bairro, até a chegada da Coca-Cola Andina e seus desdobramentos para o território em tela.

\section{1. Área de estudo}

O município de Duque de Caxias, constituinte da RMRJ, possui a população estimada para o ano de 2021 de 929.449 habitantes (IBGE, 2021). A Coca-Cola Andina está localizada no $3^{\circ}$ Distrito, no bairro da Taquara. O Plano Municipal de Saneamento Básico de Duque de Caxias (PMSB) de 2017 prevê acréscimo populacional no distrito até o ano de 2037 de 25.135 habitantes o que, consequentemente, irá causar um aumento da demanda por abastecimento de água na região.

Observa-se no PMSB (2017) que o município apresenta índices elevados no contexto econômico principalmente devido à operação da Refinaria de Duque de Caxias (REDUC) -, todavia, indicadores sociais como dados de mortalidade infantil e de saneamento básico não coincidem com o cenário economicamente positivo, o que denota um desequilíbrio entre a prosperidade econômica e social.

O Plano também evidencia que o sistema de abastecimento desse distrito é "insuficiente e, em muitas situações, com condições de qualidade água inadequadas ao consumo humano". Devido a isso, a população frequentemente é abastecida por meio de soluções individualizadas que não garantem o padrão de potabilidade necessário (PMSB, 2017). Os dados do Censo 2010 mostram que a Taquara é o bairro que apresenta a maior proporção de domicílios que utilizam o poço ou nascente na propriedade como forma de abastecimento de água, chegando a 96,32\%, enquanto menos de $1 \%$ dos domicílios possuíam acesso à rede geral de abastecimento.

Apesar dos índices pífios de saneamento básico, o bairro da Taquara, além da fábrica da Coca-Cola, abriga também atividades de mineração que pressionam ainda mais a demanda hídrica da região. Em contrapartida, o bairro possui o PNMT, inserido no Mosaico Central Fluminense. Portanto, trata-se de um quadro complexo e contraditório, que acaba por encerrar denúncias e conflitos na região.

\subsection{Histórico da instalação da Coca-Cola}

O relato abaixo é oriundo da contribuição da pesquisadora, historiadora e coordenadora do Museu Vivo de São Bento, Marlucia Santos de Souza, que gentilmente se predispôs a colaborar com o estudo.

A área da maior fábrica da Coca-Cola na América Latina abrigava, desde 1954, uma filial da Fábrica de Tecidos Nova América, denominada "Fonte Limpa". A antiga fábrica comprou um sítio em leilão chamado Santiago e instalou seu conjunto fabril, constituído sob um verdadeiro ordenamento territorial composto por uma vila operária, um clube, a escola operária - atual Colégio Estadual América Fabril -, uma praça, uma loja que vendia os próprios tecidos e a sede do sindicato operário.

Após o fechamento da fábrica em 2009 e a venda de suas terras, houve intenso processo de 
desocupação caracterizado pela demolição do patrimônio, com o intuito de expulsar a população operária da localidade. Isso deixou marcas no território por conta do desemprego em massa.

A Coca-Cola escolhe a área da antiga fábrica por conta do aquífero disponível para comercializar refrigerante e, ironicamente, água. O rio Taquara é, portanto, fundamental para a análise. Sua nascente se localiza no interior da APA Petrópolis e seu leito meandra pelo interior do PNMT. Em área adjacente ao parque, em terreno hoje ocupado pela Coca-Cola, há um reservatório de água popularmente conhecido como "reservatório da Nova América", outrora utilizado pela fábrica para lavagem dos tecidos e que até a chegada do atual empreendimento na localidade servia de lazer para banhistas. A CEDAE possuía direito de captar água deste reservatório, entretanto, suspeita-se que o preteriu devido ao acentuado estado de contaminação proveniente das operações anteriores.

Segundo o Plano de Gerenciamento de Resíduos Sólidos (PGRS) da Coca-Cola Andina (2015), a área total do terreno do empreendimento é de $2,17 \mathrm{~km}^{2}$, empregando cerca de 200 funcionários. O PGRS prevê também a instalação de oito linhas de produção, sendo três delas instaladas na primeira fase, em que a capacidade total de produção é de 402 milhões de litros de bebidas por ano; para a segunda fase, com previsão de conclusão em 2025, a intenção é operar com oito linhas de produção, pressionando ainda mais os recursos hídricos da região.

\subsection{Questões relacionadas ao DHAES}

A chegada do empreendimento trazia consigo cenários de incertezas. O Vale dos Orixás - conhecido como Parque Ecológico dos Orixás -, era um terreno baldio transformado em espaço de religiosidade que abrigava rituais praticados de forma sustentável. A água, inserida neste contexto, possui relevante valor simbólico, o que faz com que naturalmente exija preservação. O espaço desterritorializado para a operação da corporação evidencia a face utilitarista dos recursos naturais, de modo que o cercamento da terra e da água (para a corporação, recurso hídrico; para a sacralidade da religião, a materialização do divino e das forças da natureza) reproduz a lógica do capital.

Outra ação da Coca-Cola, dessa vez culminando em uma ação civil pública impetrada pela Associação Ecocidade, foi a supressão de 1,67 ha de vegetação de Mata Atlântica sem autorização do IBAMA e do ICMBio, além da dispensa de elaboração do Estudo de Impacto Ambiental (EIA/RIMA) que o empreendimento obteve junto ao INEA (MPF, 2018).

A Rio de Janeiro Refrescos $\operatorname{Ltda}^{2}$ requereu ao órgão ambiental estadual, em 2014, a Licença Prévia e de Instalação - LPI (Licença ${ }^{\circ}$ IN032342), porém, o INEA dispensou o EIA/RIMA, concluindo "que as atividades desenvolvidas não deveriam ser objeto de estudo de impacto ambiental, por não estarem no rol de atividades enumeradas como de significativo impacto ambiental" (MPF, 2018). Destarte, causa estranheza a defesa do INEA junto ao Ministério Público Federal, pois em seu relatório de vistoria em 2 de dezembro de 2014, declara:

De acordo com as Resoluções INEA $\mathrm{n}^{\circ} .52$ e 53, a atividade objeto deste Licenciamento enquadra-se no ramo de fabricação de refrigerantes (Código 27.41.99 e Critério de enquadramento - CE002), como de porte grande e alto potencial poluidor, classificada pelo Decreto Estadual no . 44.820/2014, como CLASSE 6A, e definida com ALTO IMPACTO AMBIENTAL. (INEA, 2014)

O juiz responsável acolheu as apelações do INEA e da Coca-Cola Andina e julgou improcedente a ação que solicitava suspensão da licença, elaboração do EIA/RIMA e consulta prévia às Unidades de Conservação do entorno. Esse fato levou o MPF, em 2020, a recorrer ao Tribunal Regional Federal, por considerar que "o juízo ignorou por completo os dados trazidos pelo ICMBio, e acolheu as justificativas utilizadas pelo Inea [...] em desprestígio do princípio da precaução, e colocando em

\footnotetext{
${ }^{2}$ Razão social da Coca-Cola Andina
} 
risco reservas importantes da Mata Atlântica e mananciais hídricos da região” (MPF, 2019).

Além destas questões, outro imbróglio envolvendo o empreendimento é a denúncia de moradores sobre impactos causados nos poços artesianos de suas residências no entorno da fábrica, devido ao seu uso excessivo de água em um local em que o abastecimento de água via rede geral é quase inexistente. Isso ocorre por conta da suspeita de perfuração de poços para extração de água na planta do empreendimento e da suposta captação de água pela CEDAE no interior do PNMT a fim de abastecer a Coca-Cola Andina, o que desde o início preocupou a população em relação ao desaparecimento de água nos poços, bem como em relação à contaminação do lençol freático. Também há denúncias sobre o desvio de trechos do Rio Taquara para o reservatório sob seus domínios (MOSAICO CARIOCA, 2014). Em reportagem do MPF, o ICMBio declarou que:

Embora quase todo o empreendimento, incluindo a fábrica propriamente dita, esteja fora dos limites geográficos da APA Petrópolis, existe uma captação de água em volume significativo dentro da unidade de conservação. Além disso, é importante considerar também que todas as nascentes que abastecem o Rio Taquara nessa localidade, estão protegidas pela APA Petrópolis (MPF, 2020).

Os pontos apresentados demonstram que o DHAES no bairro da Taquara é afrontado duplamente, não somente com a omissão do poder público em ofertar os serviços, mas também pela permissão para atuação de um empreendimento desse porte, ferindo ainda mais a dignidade da população local, agravando sua vulnerabilidade a partir do aumento de gastos proveniente da contratação de carrospipa para abastecimento, ou ainda por conta da convivência forçada com a insegurança hídrica.

Por fim, observa-se que, na correlação de forças entre um Estado dependente de investimento privado, uma população sistematicamente desassistida pelo poder público e uma megacorporação que traz consigo a promessa de melhorias para a região, o valor econômico da água se sobrepõe a todas as outras dimensões possíveis, cerceando o direito à vida por meio da obstaculização ao acesso à fonte de alimento primário indispensável à reprodução de todos os seres vivos.

Heller (2020) põe em relevo o fato de que o Estado ainda é o principal responsável pelo setor de água e esgotamento sanitário, contudo, outros agentes como grandes corporações, ao afetarem o gozo dos direitos das pessoas, tornam-se passíveis de penalização segundo o princípio da responsabilização do DHAES, já que podem inviabilizá-los através de poluição, excesso de captação e deslocamento de populações. Nesse caso, destaca-se que a população afetada pode responsabilizar os atores que interferem nos seus direitos. Ou seja, a sociedade civil pode se organizar e exercer pressão sobre o Estado e outros atores passíveis de responsabilização por meio de iniciativas que empoderem esses grupos marginalizados, potencializando suas reivindicações por direitos (HELLER, 2018).

\section{CONCLUSÕES}

O presente artigo pretendeu jogar luz aos efeitos da instalação da Coca-Cola Andina na região da Taquara, em Duque de Caxias. Evidenciou-se possível caso de privatização da água a partir da observação de, em um primeiro plano, a omissão do poder público para a garantia do direito humano a partir do desabastecimento hídrico e, por outro lado, pela corporação que, ao perfurar poços para sua operação, acentuou a calamitosa insegurança hídrica do local segundo as denúncias de moradores.

A intransparência do processo obstaculiza o entendimento da sequência dos fatos de maneira mais clara, sendo importante estender a análise para as questões processuais e jurídicas de modo mais detido. Espera-se que este artigo contribua para estudo sistemático sobre a questão, objetivando o empoderamento da população impactada para que esta possa melhor se organizar e permanecer na luta pelos seus direitos à água e ao esgotamento sanitário. 


\section{AGRADECIMENTOS}

À professora Ana Lucia Britto, pela orientação da pesquisa; à professora Suyá Quintslr, pela indicação para estudar o caso e compartilhamento de informações; à professora Marlúcia Santos, extremamente generosa com as valiosas informações prestadas; às valorosas contribuições de Sebastião Raulino, José Miguel Dupot, Helenita Beserra, Filipo Tardim, Cristiano Ramos; e, por fim, ao ONDAS, que diariamente nos convida à pesquisa e à luta.

\section{REFERÊNCIAS}

BORDALO, C.A.L. A gestão dos recursos hídricos à luz da ecologia política: um debate sobre o controle público versus o controle privado da água no Brasil. Cuadernos de Geografía: Revista Colombiana de Geografía, n. 17, p. 117-125, 2008.

BRITTO, A.L.N.P.; QUINTSLR, S. Políticas e programas para esgotamento sanitário na metrópole do Rio de Janeiro. Caderno Metrópoles, São Paulo, v. 22, n. 48, p. 435-456, 2020.

COCA-COLA ANDINA. Plano de Gerenciamento de Resíduos Sólidos da Coca-Cola Andina Rio de Janeiro Refrescos. 2015.

CONFLITO pela água no Parque Natural Municipal da Taquara. Mosaico Carioca, 5 mar. 2014. Disponível em: http://mosaico-carioca.blogspot.com/2014/03/conflito-pela-agua-no-parquenatural.html. Acesso em: Ago. 2021.

DARDOT, P.; LAVAL, C. Comum: ensaio sobre a revolução no século XXI. São Paulo: Boitempo Editorial, 2017.

GUDYNAS, E. Direitos da natureza: ética biocêntrica e políticas ambientais. São Paulo: Editora Elefante, 2020.

HELLER, L. Direitos humanos à água potável e ao esgotamento sanitário. Conselho dos Direitos Humanos, 73ª sessão, 2018.

HELLER, L. Realização progressiva dos direitos humanos à água e ao esgotamento sanitário. Conselho dos Direitos Humanos, 45 a sessão, 2020.

IBGE. IBGE Cidades - Duque de Caxias. 2021. Disponível em:

https://cidades.ibge.gov.br/brasil/rj/duque-de-caxias/panorama. Acesso em: Jul. 2021.

MPF - Ministério Público Federal. Ação Civil Pública no 0143156-30.2017.4.02.5118. 2018.

MPF - Ministério Público Federal. MPF apresenta recurso para suspender licença ambiental de fábrica da Coca-Cola em Duque de Caxias (RJ). 2019. Disponível em:

https://mpf.jusbrasil.com.br/noticias/733548868/mpf-apresenta-recurso-para-suspender-licencaambiental-de-fabrica-da-coca-cola-em-duque-de-caxias-rj. Acesso em: Ago. 2021.

ONU. Resolution adopted by the General Assembly on 28 July 2010. Disponível em: https://undocs.org/A/RES/64/292. Acesso em: Jul. 2021.

PMSB. Plano Municipal de Saneamento Básico de Duque de Caxias. 2017. Disponível em: http://www.inea.rj.gov.br/wpcontent/uploads/downloads/SEAS/PMSB_DUQUE_DE_CAXIAS.pdf. Acesso em: Ago. 2021.

RIBEIRO, W. A. O saneamento básico como um direito social. Revista de Direito Público da Economia-RDPE, Belo Horizonte, v. 13, n. 52, p. 229-251, 2015.

SNIS. Sistema Nacional de Informações sobre Saneamento: $2^{\circ}$ Diagnóstico dos Serviços de Água e Esgotos - 2019. Brasília, 2020. 